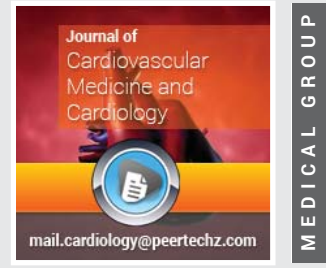

\title{
The New Carotid Braided Stent CASPERTM RX. Single center experience in 50 cases
}

Received: 30 April, 2020

Accepted: 14 May, 2020

Published: 15 May, 2020

*Corresponding author: Cabral de Andrade G, CINN Integrated Center of Neurology and Neurosurgery, Maringá, Brazil, E-mail: g.c.andrade@hotmail.com

https://www.peertechz.com

\section{Check for updates}

\section{Cabral de Andrade $\mathrm{G}^{1,2 *}$, Lesczynski $\mathrm{A}^{1,2}$, Clímaco $\mathrm{VM}^{1}$ and Pereira ER ${ }^{1}$}

'CINN- Integrated Center of Neurology and Neurosurgery, Maringá, Brazil

${ }^{2}$ Parana Hospital, Maringá, Brazil

\section{Abstract}

Purpose: Carotid stenosis, as well as dissections and pseudo dissecting aneurysms are etiological factors of Ischemic stroke. A new braided double-layer Nickel titanium Stent CASPER ${ }^{\mathrm{TM}} \mathrm{RX}$ has super elasticity, shape-memory properties, combined with re-sheathable and repositionable, improving placement accuracy in a closed cell with flow diversion capability. To evaluate in clinical implant behavicor of in many different pathologies.

Materials and methods: It was implanted 53 CASPER-RX stents in 50 lesions (average age of 67 years; 29 men and 21 women) in different pathologies, highgrade symptomatic internal carotid artery stenosis in 43(86\%) patients; and dissection in 7(4\%) being: 4 dissecting pseudo aneurysms, 2 sub endothelial spontaneous dissections and 1 sub endothelial iatrogenic dissection. In all patients we used dual antiplatelet therapy, before treatment.

Results: Technical success achieved in all patients and complication rate (4\%) and a $0 \%$ rate of neurological complications at 30 days. No stroke minor or restenosis after 6 months ultrasound or CT Scan examination FU.

Conclusion: CASPER ${ }^{\mathrm{TM}} \mathrm{RX}$ Stent conforms to tortuous anatomy, good wall apposition and a good conformation in tapered ICA-CCA segments in re sheathable delivery system. The very closed cells have a good result as a flow diverter. Technical success was achieved in all patients without clinical complications. However, we need long-term follow up to better assess the efficiency of this new device.

\section{Introduction}

The amount of devices aimed to the treatment of the atherosclerotic disease of the carotid artery and other symptomatic lesions as dissections and pseudo aneurysms. This great variety of products makes it difficult to generalize what the best treatment alternative is, because none of them has all the ideal characteristics to treat all kinds of lesions and patients.

All the self-expandable carotid stents are composed by Nickel titanium metal alloy or stainless steel (cobalt). In general, Nickel titanium stents are built with laser cut. Once they are placed in the organism, these stents have thermal memory and adapt themselves to the arterial wall according to its predefined form. The only stainless steel available is the Carotid WallStent $^{\mathrm{TM}}$ (Boston Scientific, Natick, MA, USA) of closed cells, composed by only one cobalt alloy inside a tubular structure, with $1.08 \mathrm{~mm}^{2}$ of free area from the cells.
During the analysis of the practical factors used on the choice of the stent, Bosiers, et al. [1], conclude that the most important is to minimize the risk of thromboembolic events during its implant. It is directly related to the free cell area, where in the closed cell reduces the risk of thromboembolism during and after its implantation. It happens because of the better retention of the plaque or clot between the mesh and the arterial wall, as well as reduced predisposition of plaque or clot protrusion through the mesh to the interior of the artery, especially in tortuous arteries. However, the analysis of the available data does not define a clear advantage of these two types of devices, of open or closed cells. Nevertheless, there are tendencies that support recommendations of certain stents for specific morphological injury [2]. The ideal stent may cover safely the plate and have good adjustment on the arterial wall. In order to do so, it must have the right balance between flexibility, burst pressure and radial strength [3]. 


\section{Method}

The study was conducted from 2015 to 2018, with prospective data collection, in a singular center, with individual interventional neuroradiologist, in 50 patients (average age of 67 yo; 29 male and 21 female) which included symptomatic atherosclerotic stenosis in 42 patients (average of $80 \%$ ) and dissection with 4 pseudo aneurysm, 3 dissections ( 2 spontaneous and 1 iatrogenic) all evaluated by ultrasound, MRI angiography or angio scan. In all cases was used closed cell stent CASPERRX. A total of 53 stents implanted [7×30(12), $7 \times 40(1), 8 \times 25(4)$, $8 \times 30(12), 8 \times 40(21), 9 \times 30(3)]$, using multiple access guiding catheters, all $7 \mathrm{~F}$, as well as various kind of cerebral protection filters, micro-guides and angioplasty balloons, compatible with Stent (Table 1)

\section{Casper-RX Stent}

CASPER-RX stent (Microinvention, California, Tustin, USA) has a unique design, made with braided Nickel titanium wires with double layer developed to sustain the embolic prevention. It prevents thrombus fragments from being detached and carried by blood flow with fragments trapped between the stent layers. Structure made of closed cell reaching a 375-500 $\mu \mathrm{m}$ cell size with a flexible braid allowing good accommodation in the arterial wall. The free cell size is compatible with about $1 / 4$ of the closed cell stent, which has the lowest free area (Wallstent). It can be re-sheathable and repositioned (the implantation of up to $50 \%$ is recommended). It has a low profile, which allows a better crossability in case it is necessary to surpass the stent or the use of a second stent. In addition, an expandable stent

Table 1: Clinical characteristics of 50 patients with symptomatic high grade carotid stenosis and dissection, as well as all used devices and procedure complications.

\begin{tabular}{|c|c|c|c|c|c|c|c|c|c|}
\hline $\begin{array}{c}\text { Case } \\
n^{\circ}\end{array}$ & Sex & Age & Side & Pathology & & Filter/Guide Wire & $\begin{array}{l}\text { Stent/Size/ } \\
\text { Number }\end{array}$ & $\begin{array}{c}\text { Balloon } \\
\text { angioplasty }\end{array}$ & Complicat \\
\hline 1. & $\hat{o}$ & 79 & Right & Carotid stenosis & $>70 \%$ & Emboshield Nav6 & CASPER 7X30mm(1) & Viatrac $6 \times 20 \mathrm{~mm}$ & No \\
\hline 2. & $\hat{\sigma}$ & 59 & Right & Carotid stenosis & $80 \%$ & Emboshield Nav6 & CASPER 7X30mm (1) & Viatrac $6 \times 20 \mathrm{~mm}$ & No \\
\hline 3. & q & $68 c c$ & Right & Carotid stenosis & $>90 \%$ & Emboshield Nav6 & CASPER 9X30mm (1) & $\begin{array}{l}\text { NC Trek 3x20mm } \\
\text { Viatrac } 6 \times 20 \mathrm{~mm}\end{array}$ & No \\
\hline 4. & $\hat{\sigma}$ & 59 & Left & Carotid stenosis & $>70 \%$ & Emboshield Nav6 & CASPER 7X30mm (1) & Viatrac $6 \times 20 \mathrm{~mm}$ & No \\
\hline 5. & q & 58 & Left & Dissecting pseudoan & leurysm & Traxcess $0.014^{\prime \prime}$ & CASPER 8X25mm (1) & No & No \\
\hline 6. & $\hat{\sigma}$ & 75 & Right & Carotid stenosis & $>70 \%$ & Emboshield Nav6 & CASPER 8X30mm (1) & Viatrac $6 \times 20 \mathrm{~mm}$ & No \\
\hline 7. & q & 64 & Right & Dissection +intra lum & inal clot & FilterWire EZ & CASPER 7X30mm (1) & No & No \\
\hline 8. & $\hat{\sigma}$ & 31 & Left & Dissecting pseudoane & „rysms (2) & Traxcess $0.014^{\prime \prime}$ & $\begin{array}{l}\text { CASPER } 8 \times 30 \mathrm{~mm}(1) \\
\text { CASPER } 9 \times 30 \mathrm{~mm}(1)\end{array}$ & No & No \\
\hline 9. & $\hat{0}$ & 64 & Left & Carotid stenosis & $80 \%$ & Emboshield Nav6 & $\begin{array}{l}\text { CASPER } 8 \times 30 \mathrm{~mm}(1) \\
\text { CASPER } 7 \times 30 \mathrm{~mm}(1)\end{array}$ & Viatrac $6 \times 20 \mathrm{~mm}$ & Dissecti \\
\hline 10. & $\hat{\sigma}$ & 68 & Left & Carotid stenosis & $90 \%$ & Emboshield Nav6 & CASPER 8X30mm (1) & Sterling Monorail $6 \times 20 \mathrm{~mm}$ & No \\
\hline 11. & $\hat{\sigma}$ & 75 & Right & Carotid stenosis & $>90 \%$ & $\begin{array}{c}\text { Traxcess } 0.014 " \\
+ \\
\text { Emboshield Nav6 }\end{array}$ & CASPER 8X40mm (1) & $\begin{array}{l}\text { NC Trek } 3,5 \times 15 \mathrm{~mm} \\
\text { Viatrac } 6 \times 20 \mathrm{~mm}\end{array}$ & No \\
\hline 12. & $q$ & 67 & Left & Carotid stenosis & $>90 \%$ & $\begin{array}{c}\text { Traxcess } 0.014 " \\
+ \\
\text { Emboshield Nav6 }\end{array}$ & CASPER 7X30mm (1) & $\begin{array}{l}\text { NC Trek } 3 \times 20 \mathrm{~mm} \\
\text { Viatrac } 6 \times 20 \mathrm{~mm}\end{array}$ & No \\
\hline 13. & q & 39 & Left & $\begin{array}{l}\text { Dissecting pseudoan } \\
\text { Subendothelial diss }\end{array}$ & $\begin{array}{l}\text { eurysm+ } \\
\text { ection }\end{array}$ & Emboshield Nav6 & CASPER 8X40mm (2) & No & No \\
\hline 14. & q & 65 & Left & Carotid stenosis & $80 \%$ & Emboshield Nav6 & CASPER 9X30mm (1) & Viatrac 6x20mm & No \\
\hline 15. & q & 76 & Left & Carotid stenosis & $>70 \%$ & Emboshield Nav6 & CASPER 8X30mm (1) & Viatrac $6 \times 20 \mathrm{~mm}$ & No \\
\hline 16. & $\delta$ & 78 & Right & Carotid stenosis & $>70 \%$ & Emboshield Nav6 & CASPER 8x40mm (1) & Viatrac 6x20mm & No \\
\hline 17. & 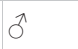 & 79 & Right & Carotid stenosis & $90 \%$ & Emboshield Nav6 & CASPER 7X30mm (1) & Viatrac 6x20mm & No \\
\hline 18. & $\hat{\sigma}$ & 84 & Right & Carotid stenosis & $>80 \%$ & Emboshield Nav6 & CASPER 8X40mm (1) & Viatrac $6 \times 20 \mathrm{~mm}$ & No \\
\hline 19. & q & 68 & Left & Carotid stenosis & $>90 \%$ & $\begin{array}{c}\text { Traxcess } 0.014 " \\
+ \\
\text { Emboshield Nav6 }\end{array}$ & CASPER 7X30mm (1) & $\begin{array}{l}\text { NC Trek } 3,5 \times 20 \mathrm{~mm} \\
\text { Viatrac } 6 \times 20 \mathrm{~mm}\end{array}$ & No \\
\hline 20. & $\hat{\sigma}$ & 67 & Right & Carotid stenosis & $80 \%$ & Emboshield Nav6 & CASPER 8X30mm (1) & Sterling Monorail $6 \times 20 \mathrm{~mm}$ & No \\
\hline 21. & 운 & 29 & Left & Traumatic Dissec & tion & Traxcess $0.014^{\prime \prime}$ & CASPER 8X30mm(1) & No & No \\
\hline 22. & $\hat{\sigma}$ & 86 & Right & Carotid stenosis & $>90 \%$ & Emboshield Nav6 & CASPER 8X25mm (1) & Sterling Monorail $6 \times 20 \mathrm{~mm}$ & No \\
\hline 23. & q & 66 & Right & Carotid stenosis & $>80 \%$ & Emboshield Nav6 & CASPER 8X40mm(1) & Viatrac 6x20mm & No \\
\hline 24. & $\hat{\sigma}$ & 72 & Left & Carotid stenosis & $>90 \%$ & Emboshield Nav6 & CASPER 7X30mm (1) & Viatrac $6 \times 20 \mathrm{~mm}$ & No \\
\hline 25. & $\hat{o}$ & 58 & Right & Carotid stenosis & $80 \%$ & Emboshield Nav6 & CASPER 8X40mm(1) & Viatrac $6 \times 20 \mathrm{~mm}$ & No \\
\hline 26. & q & 58 & Left & Carotid stenosis & $60 \%$ & Emboshield Nav6 & CASPER 8X25mm (1) & Viatrac $6 \times 20 \mathrm{~mm}$ & No \\
\hline 27. & q & 76 & Left & Carotid stenosis & $90 \%$ & Emboshield Nav6 & CASPER 8X40mm(1) & Viatrac 6x20mm & No \\
\hline
\end{tabular}




\begin{tabular}{|c|c|c|c|c|c|c|c|c|c|}
\hline 28. & $\delta$ & 54 & Left & Carotid stenosis & $90 \%$ & Emboshield Nav6 & CASPER 8X40mm(1) & Viatrac $6 \times 20 \mathrm{~mm}$ & No \\
\hline 29. & q & 79 & Right & Carotid stenosis & $>80 \%$ & Emboshield Nav6 & CASPER 8X40mm(1) & $\begin{array}{l}\text { NC Trek } 3,5 \times 12 \mathrm{~mm} \\
\text { Viatrac } 6 \times 20 \mathrm{~mm}\end{array}$ & No \\
\hline 30. & q & 66 & Right & Carotid stenosis & $>70 \%$ & Emboshield Nav6 & CASPER 8X25mm(1) & Viatrac $6 \times 20 \mathrm{~mm}$ & No \\
\hline 31. & q & 81 & Left & Carotid stenosis & $80 \%$ & FilterWire EZ & CASPER 7x30mm(1) & Viatrac $6 \times 20 \mathrm{~mm}$ & No \\
\hline 32. & $\delta$ & 50 & Left & Dissection & & Emboshield Nav6 & CASPER 8X40mm(1) & Viatrac 6x20mm & No \\
\hline 33. & q & 36 & Left & Dissection & & Emboshield Nav6 & CASPER 7x30mm(1) & Viatrac $6 \times 20 \mathrm{~mm}$ & No \\
\hline 34. & $\delta$ & 75 & Right & Carotid stenosis & $>70 \%$ & Emboshield Nav6 & CASPER 8X40mm(1) & Viatrac $6 \times 20 \mathrm{~mm}$ & No \\
\hline 35. & q & 75 & Right & Carotid stenosis & $>70 \%$ & Emboshield Nav6 & CASPER 8X40mm(1) & Viatrac $6 \times 20 \mathrm{~mm}$ & No \\
\hline 36. & q & 69 & Left & Carotid stenosis & $>70 \%$ & Emboshield Nav6 & CASPER 8X40mm(1) & Viatrac $6 \times 20 \mathrm{~mm}$ & No \\
\hline 37. & $\delta$ & 75 & Left & Carotid stenosis & $>80 \%$ & Emboshield Nav6 & CASPER 8X40mm(1) & Viatrac $6 \times 20 \mathrm{~mm}$ & No \\
\hline 38. & $\delta$ & 75 & Left & Carotid stenosis & $70 \%$ & Emboshield Nav6 & CASPER 8X40mm(1) & Viatrac $6 \times 20 \mathrm{~mm}$ & No \\
\hline 39. & $\delta$ & 76 & Left & Carotid stenosis & $90 \%$ & Emboshield Nav6 & CASPER 8X40mm(1) & Viatrac $6 \times 20 \mathrm{~mm}$ & No \\
\hline 40. & $\delta$ & 75 & Left & Carotid stenosis & $70 \%$ & Emboshield Nav6 & CASPER 8X40mm(1) & Viatrac $6 \times 20 \mathrm{~mm}$ & No \\
\hline 41. & $\delta$ & 76 & Left & Carotid stenosis & $90 \%$ & Emboshield Nav6 & CASPER 8X30mm(1) & Viatrac $6 \times 20 \mathrm{~mm}$ & No \\
\hline 42. & q & 67 & Left & Carotid stenosis & $80 \%$ & Emboshield Nav6 & CASPER 8X40mm(1) & Viatrac $6 \times 20 \mathrm{~mm}$ & $\begin{array}{c}\text { Femural } \\
\text { hematoma }\end{array}$ \\
\hline 43. & $\hat{0}$ & 69 & Right & Carotid stenosis & $80 \%$ & Emboshield Nav6 & CASPER 8X30mm(1) & Viatrac $6 \times 20 \mathrm{~mm}$ & No \\
\hline 44. & q & 64 & Left & Carotid stenosis & $75 \%$ & Emboshield Nav6 & CASPER 8X30mm(1) & Viatrac 6x20mm & No \\
\hline 45. & $\delta$ & 65 & Right & Carotid stenosis & $70 \%$ & Emboshield Nav6 & CASPER 8X40mm(1) & Viatrac $6 \times 20 \mathrm{~mm}$ & No \\
\hline 46. & q & 53 & Left & Dissection & & Emboshield Nav6 & CASPER 7x30mm(1) & Viatrac $6 \times 20 \mathrm{~mm}$ & No \\
\hline 47. & $\delta$ & 73 & Left & Carotid stenosis & $70 \%$ & Emboshield Nav6 & CASPER 8X30mm(1) & Viatrac $6 \times 20 \mathrm{~mm}$ & No \\
\hline 48. & $\hat{0}$ & 88 & Left & Carotid stenosis & $80 \%$ & FilterWire EZ & CASPER $7 \times 40 \mathrm{~mm}(1)$ & Sterling Monorail $6 \times 20 \mathrm{~mm}$ & No \\
\hline 49. & q & 68 & Left & Carotid stenosis & $>70 \%$ & Emboshield Nav6 & CASPER 8X40mm(1) & Viatrac $6 \times 20 \mathrm{~mm}$ & No \\
\hline 50. & $\hat{\delta}$ & 71 & Left & Carotid stenosis & $80 \%$ & Emboshield Nav6 & CASPER 8X30mm(1) & Sterling Monorail $6 \times 20 \mathrm{~mm}$ & No \\
\hline
\end{tabular}

settles according to the vessel diameter, and can take the conical shape (with a maximum range of $3.5 \mathrm{~mm}$ ). Delivery system: $5 \mathrm{~F}$, minimum guiding catheter 7-F, $143 \mathrm{~cm}$ of length, fast switch, 0.014 " guide. It also has the ability of redirecting the flow.

\section{Data collection}

The collected data included different types of lesions in carotid artery, the endovascular treatment performed, immediate results and the clinical follow-up at 30 days and three and six months imaging follow-up. The collected data referring to the patients regarded sex, age, laterality and type of lesion, immediate complications and follow-up. Referring to the treatment, the collection aimed at the technique used, with or without the cerebral protection filter, the pre or post dilatation with the angioplasty balloon and the size and quantity of implanted stents. In addition, complications and clinical follow-up at the 3oth day and with the control tests (USG or Angio Scanner) which included ischemic event, morbimortality, relapse or necessity of re-treatment. The treatment included only one type of braided wire stent, closed cells and with the possibility of repositioning, of varied sizes according to the arterial diameter, with numerous other compatible materials like cerebral protection filter, micro-guide and angioplasty balloon.

\section{Treatment indication}

Aiming the evaluation of the CASPER-RX stent use in different pathologies of the extra cranial internal carotid artery, patients with atheromatous disease with stenosis between > $70 \%$ and $>90 \%$, and all with ischemic symptoms even the use of antiplatelet drugs, were previously evaluated with ultrasound, angio MRI or angio tomography and lesions confirmed by angiography. As patients with acute and sub-acute disease with spontaneous and sub occlusive iatrogenic dissection and pseudo aneurysms, also with ischemic symptoms. Histories of brief cases and radiographic images in a case of severe and symptomatic stenosis $>90 \%$, symptomatic sub occlusive dissection and sintomatic pseudo aneurysm associated with dissecting shown in Figures 1 (a,b,c,d,e and f), 2(a,b,c,d,e and f) and $3(\mathrm{a}, \mathrm{b}, \mathrm{c}, \mathrm{d}$ and e) respectively.

\section{Endovascular treatment}

The procedure was performed under local anesthesia with sedation or general anesthesia. All patients had previous use of dual antiplatelet therapy with clopidogrel $75 \mathrm{mg} /$ day and aspirin $200 \mathrm{mg} /$ day. In 05 of the cases (in sub occlusive atheromatous disease with stenosis between $>80$ and $\geq 90 \%$ required pre coronary balloon dilation (cases $\mathrm{n}^{0} 3, \mathrm{n}^{0} 11, \mathrm{n}^{0} 12, \mathrm{n}^{\mathrm{o}} 19$ and $\mathrm{n}^{0}{ }_{29}$ ) (Table 1) (Figure 1c). It was used cerebral protection system in all cases of atheromatous disease, in cases of dissection and pseudo aneurysm, only micro-guide 0.014 was used. In one dissection case $\left(\right.$ case $^{0}{ }^{0}$ ) where there was the presence of free intraluminal clot, it is used a cerebral protection system. All patients received 5,000 units of heparin during the procedure and atropine (0.5 $\mathrm{mg}$ ) prior to stent implantation. Patients continued with dual antiplatelet therapy after the procedure. 


\section{Results}

All the stents, a total of 53 and different measures [7×30(12), $7 \times 40(1), 8 \times 25(4), 8 \times 30(12), 8 \times 40(21), 9 \times 30(3)]$ (Table 1), were satisfactorily implanted, without any difficulties with the navigation and delivery systems, even with the use of telescoped stents. The rate of complications was $4 \%$, a case with a small area dissected of just detachment to the amount of stent, without clinical manifestations and it was opted to put a second telescoped stent to avoid the risk of dissection (case $n^{\circ} 9$ ) and femoral hematoma in another case. In two other cases, the use of more than one stent was necessary, in a telescoped way, due to the presence of multiple lesions. Two pseudo aneurysms (case $n^{\circ} 8$ ), and a pseudo aneurysm associated with extensive dissection (case $\mathrm{n}^{\mathrm{0}}{ }^{13}$ ) (Figure $3(\mathrm{a}, \mathrm{b}, \mathrm{c}, \mathrm{d}$ and $\mathrm{e})$ ), there were no difficulties to navigate to the implant system through the first implanted stent, as well as the release of a second stent telescoped smoothly. All the patients had a favorable clinical evolution, no thromboembolic event at the clinical and imaging (ultrasound and/or angiography carotid tomography) followup that showed patency of the stents in all cases, as well as the
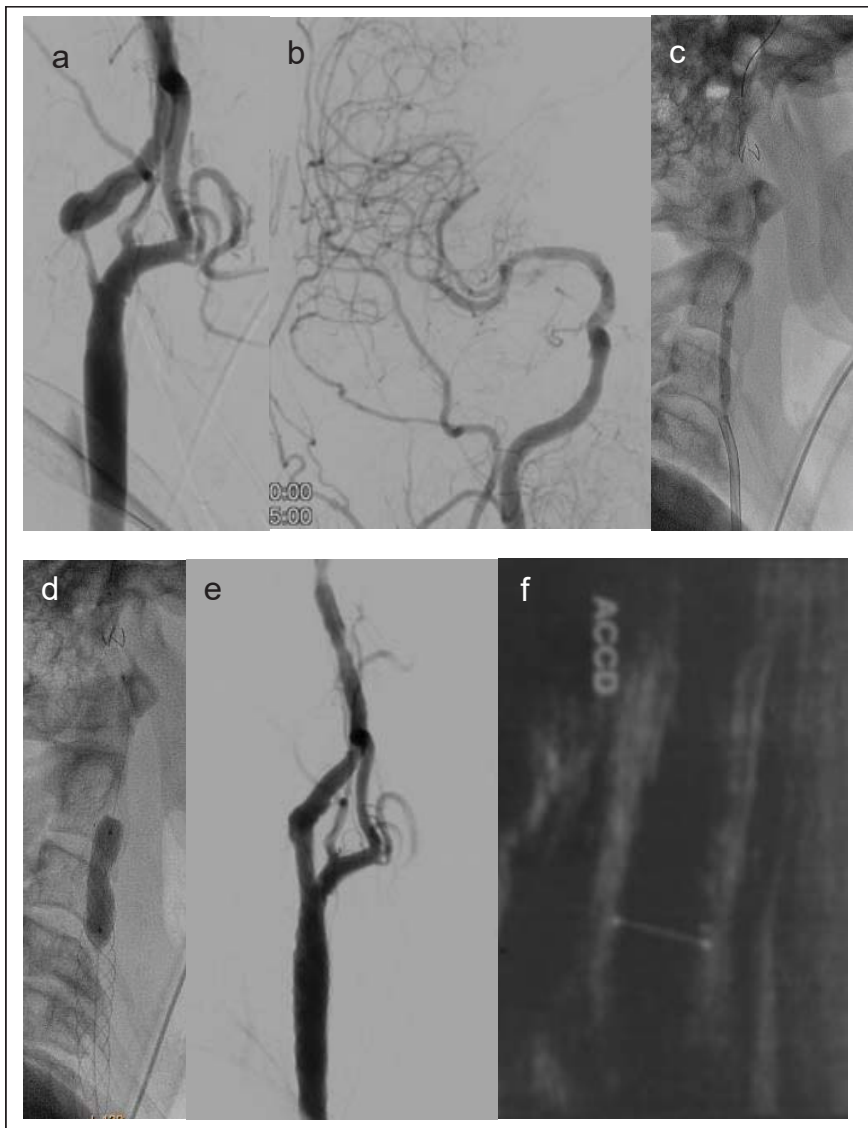

Figure 1: Case 03. In a 68-year-old woman who presented with left-sided hemiparesis. A right CCA angiogram showed carotid high grade atheromatosis with $>90 \%$ stenosis(a) and without good intracranial vascularization by the absence of the cerebral anterior artery(b). First was performed a pre dilatation with a $3 \mathrm{~mm}$ coronary ballon and cerebral protection system Emboshield Nav(c) and implanted a carotid Stent Casper Rx $(9 \times 30 \mathrm{~mm})$ and post Stent dilatation with $6,0 \times 20 \mathrm{~mm}$ carotid ballon(d). The final post Stent angiography control, with a good implantation of the Stent and total recanalization of the ICA(e) and 6 months followup ultrassond shows preserved flow with no turbulence or recurrent stenosis(f). Abbreviations: CCA=carotid common artery; ICA=internal carotid arteryc
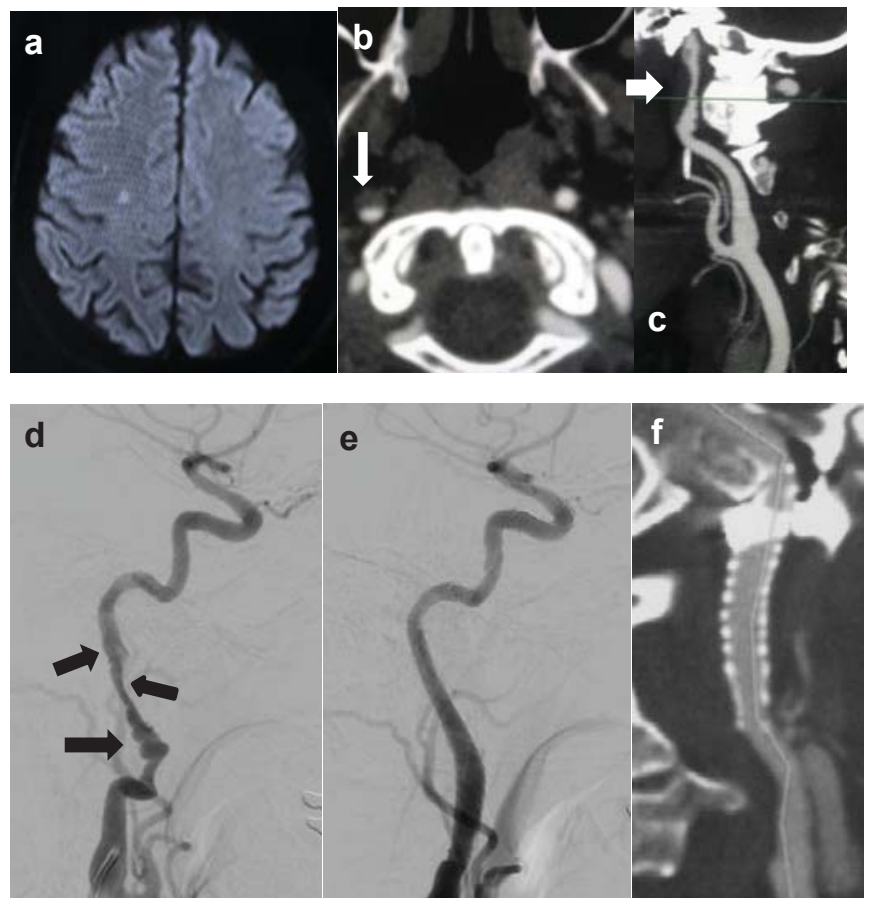

Figure 2: Case 07. In a 64-year-old woman who presented with left-sided hand paresis after hypertensive peak. A MRI diffusion showing a small ischemic area in the right motor cortex(a). An axial TC scan and right CCA angio TC reconstruction, showed extensive intraluminal clot(white arrows)(b) and (c). A right CCA angiogram confirm a dissection and intraluminal clot(black arrows)(d) and showed carotid fibromuscular dysplasia. Was performed an angioplasty with carotid Stent Casper Rx $(7 \times 30 \mathrm{~mm})$ and cerebral protection system Filter Wire EZ without ballon angioplasty(d). The final post Stent angiography control, with a good implantation of the Stent and total recanalization of the ICA(e) and 6 months follow-up angio TC shows preserved flow without recurrent stenosis.

Abbreviations: MRI= Magnetic Resonance Imaging; CCA=carotid common artery; ICA=internal carotid artery

absence of re-stenosis, occlusion of pseudo aneurysms and complete recanalization in cases of dissection.

\section{Study limitation}

It is a retrospective non-randomized analysis. Even though one could argue that device selection was biased, in all patients there was symptomatic ischemic lesion previously stenting treatment.

\section{Discussion}

The nature of most of the neurological events in patients with carotid artery stenosis is not related to the brain hyper perfusion, but have an embolic origin [4].

As demonstrated in the randomized multi-centric prospective trials, carotid endarterectomy (CEA), with the removal of plaque and the source of emboli, it is the gold standard for reducing stroke in symptomatic and asymptomatic patients with significant carotid stenosis (NASCET) [4]. However, carotid artery angioplasty and use of stent has become an alternative to endarcterectomy [5]. In contrast to surgical therapy, $50 \%$ to $66 \%$ of stroke after CAS occurs within the first 4 weeks, which can be attributed to embolization of thrombus or plaque through the structure of the stent [6]. 


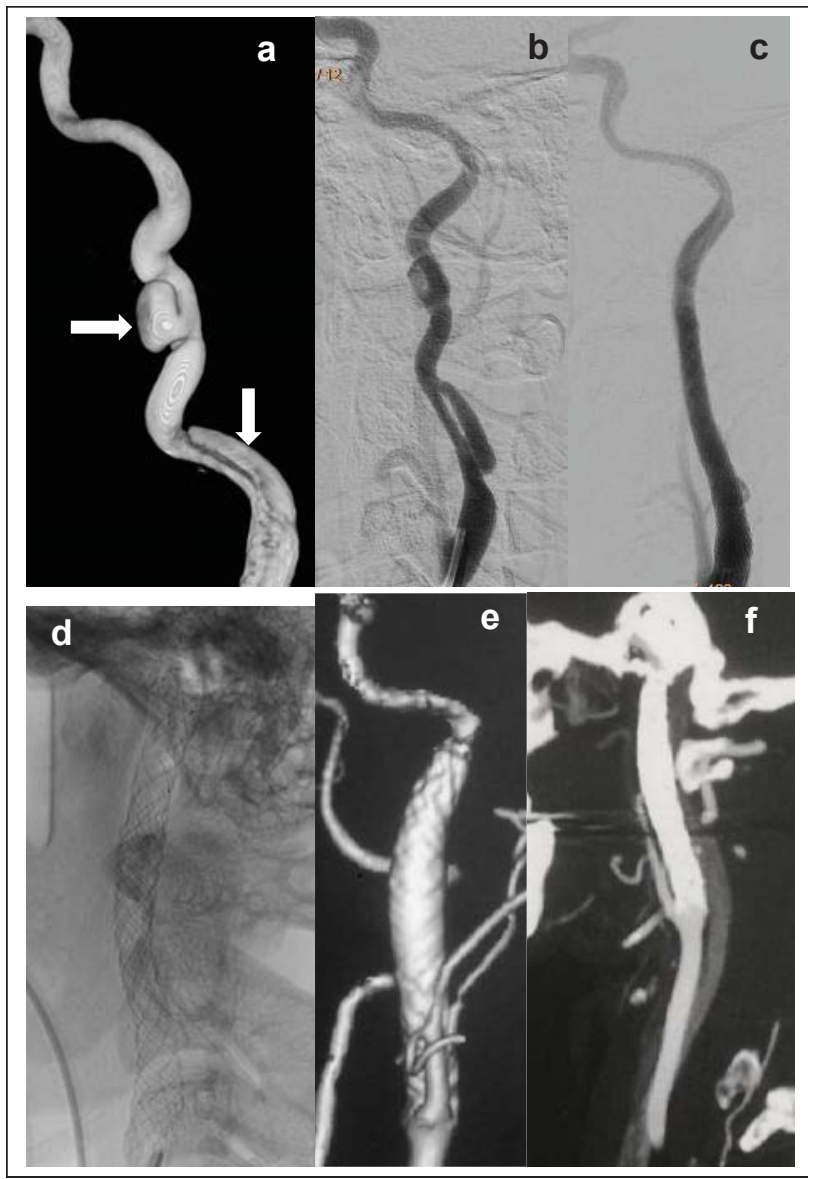

Figure 3: Case 13. In a 39-year-old woman who presented with right-sided hemipaparesis without ischemic lesions. History of polycystic kidney disease. A left CCA angiogram and 3D reconstruction showed an extensive dissection and a pseudo dissecting aneurysm(white arrows)(a) and (b). Was performed an angioplasty with a carotid Stent Casper Rx $(8 \times 40 \mathrm{~mm})$ and cerebral protection system Emboshield Nav without ballon angioplasty. The final post Stent angiography control, with a good implantation of the Stent and total recanalization of the ICA and immediate resolution of the dissection and occlusion of the pseudoaneurysm by characteristic of flow diverter(c). Good accommodation and visualization of the mesh stent(d) and 6 months follow-up angio TC 3D reconstruction and MIP shows good accommodation of the stent, preserved flow without recurrent stenosis and occlusion od the pseudoaneurysm (e) and ( $f$ ). Abbreviations: CCA=carotid common artery; ICA=internal carotid artery

Arterial dissections can be spontaneous or traumatic/ iatrogenic, corresponding to $25 \%$ of ischemic strokes in young people up to 45 years old, with favorable outcome in $75 \%$ of patients, but with a mortality of about $4 \%$. Clinical treatment with antiplatelet therapy is still the treatment of choice for these lesions, according to "Cervical Artery Dissection in Stroke Study" (CADISS) [8]. The selection criteria of the candidates for stent therapy include: 1) clinical failure of medical therapy (presence of recurrent TIA, fluctuating neurological signs or neurological deterioration); 2) impending stroke attributable to significant stenosis/occlusion with poor collateral circulation as well as failure of the circle of Willis and decreased perfusion in parenchymal capillary angiographic phase, CT, or MR imaging studies; 3) contraindication for anticoagulation because of intracranial or systemic bleeding; 4) evidence of symptomatic thromboembolic occlusion of cerebral vessels; 5) contralateral CA stenosis/occlusion; 6) need of elective occlusion of the
ICA contralateral to another disease; and 7) the need to avoid increasing flow through the anterior communicating artery because of an associated aneurysm $[9,10]$. In case of sintomatic dissection and arterial subocclusion case stent success rate of $99 \%$ and the procedural complication rate was $1.3 \%$, being a safe and effective method in the treatment of these lesions in selected cases, demonstrating viability of this paradigm [11,12].

The pseudo aneurysm of the carotid artery has as the most common causes the atherosclerotic degeneration and congenital connective tissue diseases such as fibromuscular dysplasia or Bechet's disease or iatrogenic. They can also result from trauma, cerebral vascular dissection or may be iatrogenic as a complication of carotid or cerebral angiography, may be recommended because of relevant thromboembolism risk, and treatment with stenting, especially in distal lesions of pre cerebral internal carotid artery [13,14]. Among the variety of available stents, recent studies have emphasized the superiority of the coated stents for the treatment of large pseudo aneurysms while stent implantation is recommended for small defects [15].

Many features must be taken into consideration in choosing the stent according to the pathology and the patient's anatomy. The scaffolding properties of the stent (defined as the amount of support given to the vessel wall by stents) are of great importance in order to minimize the risk of embolisms, as well as the free cell area from the results of BIC register [16]. We have learned that stents with this profile are better at retaining material behind the support, which results in significant differences in event rates compared to open cell stents.

The open cell and closed cell stents have been evaluated in several publications with the intention to relate its design with immediate results and long-term treatment of occlusive atherosclerotic disease of the carotid artery. Many conclude that in most cases treated with closed cell design stent there was significantly fewer ischemic stroke and death after 30 days, compared to those treated with stents designed with open cells [17]. In multicenter evaluation, retrospective, nonrandomized, with large group (cohort) of patients and use of multiple closed and open cell stents, was observed a higher rate of ischemic complications after the procedure, within 30 days, with open cell stents, showing a rate of $3.4 \%$ against $1.3 \%$ in closed cell stents $[16$.

Another characteristic of the stent is its flexibility, which is reflected in its ability to adapt to vessel tortuosity during its use. In terms of flexibility, closed cell stents, both Nickel titanium and stainless steel do not perform as well as their homologues open cells. Another feature is the ability to adapt to conic anatomy of this region of the carotid artery (vessel wall adaptability). Therefore, the ability of supporting/scaffolding of the current generation of devices is compromised by insufficient flexibility. The improvement in stent design should focus primarily on the combination of scaffolding properties and flexibility [1].

The flexibility and pliability of the stents are related to its configuration, an open cell stent allows greater discovered gaps and is more pliable, making it more suitable for tortuous arteries, where reducing the need for associated handling may 
reduce the embolic potential and folds (kinking). On the other hand, a larger free cell area allows greater exposure of the plaque, possibly increasing the embolic potential. Closed cell stents provide greater plaque coverage, but are more rigid and require more vigorous manipulation for use, which can also increase the risk of embolic complications $[18,19]$. A prospective randomized study found no significant difference in the restricted diffusion lesions in MRI when comparing open and closed cell models [20].

The experimental results showed some similarities with the WallStent carotid stent, with relatively low radial force $(0,011$ $\mathrm{N} / \mathrm{mm}$ CASPER RX and $0.020 \mathrm{~N} / \mathrm{mm}$ Wall stent carotid), a very high pressure collapse, bending stiffness almost similar. However, in contrast with the WallStent carotid, adaptation to the arterial wall and curved as in model is better with Casper RX [21].

Another interesting feature of this new device is its flow redirection capability when used in pseudo aneurysms pre cerebral segment of the carotid arteries. Its double braided Nickel titanium layer creates an intraluminal flow bypass, reducing the flow into the aneurysmal sac, and accelerating the formation of thrombus, while maintaining the normal blood flow, in addition, the telescoped stenting coaxial manner causes an increase in the mesh density and better flow redirection with higher embolic protection [22].

In this initial experience, with the medium term follow-up of the patients involved, the use of this new device, the RX CASPER stent, none of them had problems regarding independent navigability of the aortic arch type 1 to 3 or ICA tortuous or not. Other characteristics of the device were observed in this series, as its flexibility, good accommodation according to the vascular anatomy with good navigability. It does not have a high radial strength, however it was sufficient without the need of angioplasty in dissection or pseudo aneurysm and in cases of atheromatous disease, it behaved with good accommodation in the arterial wall after angioplasty. Its crossability also proved to be satisfactory in cases where there was a need of the telescoped stent. Its function as a redirector device flow also proved efficient in cases of pseudo aneurysm occlusion immediately after implantation of the stent, similar to devices diverters of flow used in intracranial aneurysms. Surveillance ultrasound and CT scans documented good wall apposition in all patients and $0 \%$ rate of neurological complications at 30 days. In this series we try to observe the behavior of the device with respect to its navigability, risk of intr procedural complications and medium term follow up. There was no kind of early or late thromboembolic complications related to the use of the device.

\section{Conclusion}

The CASPER RX stent has the design with double layer of braided Nickel titanium wire with a lower free area of closed cells with re sheathable system. It appears to be safe and effective, with good navigability and enough radial strength with good accommodation in the arterial wall, to treat extra cranial stenosis of the ICA, as well as sub occlusive dissecting symptomatic or high risk lesions, including high lesions in the petrous segment but also in the treatment of the pseudo aneurysm with possibility of immediate occlusion by characteristics for flow redirection. In this series, cases of atheromatous disease it was used cerebral embolic protection device, except in cases of dissection or pseudo aneurysm, however the need for an embolic protection device with this stent should be investigated. We had early or late thromboembolic complications in this series. However, a comparative study with other closed cell devices is necessary evaluate the long term results of this stent.

\section{Ethical standards and patient consent}

We declare that all human and animal studies have been approved by the [insert appropriate ethics committee] and have therefore been performed in accordance with the ethical standards laid down in the 1964 Declaration of Helsinki and its later amendments. We declare that all patients gave informed consent prior to inclusion in this study.

\section{References}

1. Bosiers M, Deloose K, Verbist J, Peeters P (2005) Carotid artery stenting: which stent for which lesion? Vascular 13: 205-210. Link: https://bit.ly/2yR9SaR

2. Nikas DN, Kompara G, Reimers B (2011) Carotid stents: which is the best option? J Cardiovasc Surg (Torino) 52: 779-793. Link: https://bit.ly/35Tk9iO

3. Müller-Hülsbeck S, Schäfer PJ, Charalambous N, Schaffner SR, Heller M, et al (2009) Comparison of carotid stents: an in-vitro experiment focusing on stent design. J Endovasc Ther 16: 168-177. Link: https://bit.ly/3buaY9A

4. North American Symptomatic Carotid Endarterectomy Trial (NASCET) Collaborators. Barnett HJM, Taylor DW, Haynes RB, Sackett DL, et al. (1991) Beneficial effect of carotid endarterec-tomy in symptomatic patients with high-grade carotid stenosis. N Engl J Med 325: 445-453.Link: https://bit.ly/2yPSSBG

5. Cremonesi A, Castriota F, Secco GG, Macdonald S, Roffi M (2015) Carotid artery stenting: an update. Eur Heart J. 36: 13-21. Link: https://bit.ly/3cES15q

6. Piorkowski M, Kläffling $\mathrm{C}$, Botsios $\mathrm{S}$, Zerweck C, Scheinert S, et al. (2015) Postinterventional microembolism signals detected by transcranial Doppler ultrasound after carotid artery stenting. Vasa 44: 49-57. Link: https://bit.ly/2SViHav

7. Touzé E, Gauvrit JY, Meder JF, Mas JL (2005) Prognosis of cervical artery dissection. Front Neurol Neurosci 20: 129-139. Link: https://bit.ly/2TgT8B1

8. Kennedy F, Lanfranconi S, Hicks C, Reid J, Gompertz P, et al. (2012) Antiplatelets vs anticoagulation for dissection: CADISS nonrandomized arm andmeta-analysis. Neurology 79: 686-689.Link: https://bit.ly/2WsxJ9W

9. Donas KP, Mayer D, Guber I, Baumgartner R, Genoni M, et al. (2008) Endovascular repair of extracranial carotid artery dissection: current status and level of evidence. J Vasc Interv Radiol 19: 1693-1698. Link: https://bit.ly/2zw1D3W

10. Biondi A, Katz JM, Vallabh J, Segal AZ, Gobin YP (2005) Progressive symptomatic carotid dissection treated with multiple stents. Stroke 36 e80-e82. Link: Link: https://bit.ly/2Ah3wlk

11. Ohta H, Natarajan SK, Hauck EF, Khalessi AA, Siddiqui AH, et al. (2011) Endovascular stent therapy for extracranial and intracranial carotid artery dissection: single-center experience. J Neurosurg 115: 91-100. Link: https://bit.ly/3fJotFY

12. Pham MH, Rahme RJ, Arnaout O, Hurley MC, Bernstein RA, et al. (2011) Endovascular stenting of extracranial carotid and vertebral artery 
dissections: a systematic review of the literature. Neurosurgery. 68: 856-866. Link: https://bit.ly/2YXr1KA

13. Li Z, Chang G, Yao C, Guo L, Liu Y, et al. (2011) Endovascular stenting of extracranial carotid artery aneurysm: a systematic review. Eur J Vasc Endovasc Surg 42: 419-426. Link: https://bit.ly/2zBrG9L

14. Maras D, Lioupis C, Magoufis G, Tsamopoulos N, Moulakakis K, et al (2006) Covered stent-graft treatment of traumatic internal carotid artery pseudoaneurysms: a review. Cardiovasc Intervent Radiol 29: 958-968. Link: https://bit.ly/3fJmoJY

15. Welleweerd JC, Jan de Borst G, de Groot D, van Herwaarden JA, Lo RT, et al. (2015) Bare metal stents for treatment of extracranial internal carotid artery aneurysms: long term results. J Endovasc Ther 22: 130-134. Link: https://bit.ly/3dDBEq0

16. Bosiers M, De Donato G, Deloose K, Verbist J, Peeters P, et al. (2007) Does free cell area influence the outcome in carotid artery stenting? Eur $\mathrm{J}$ Vasc Endovasc Surg 33: 135-141.Link: https://bit.ly/2TOFCBe

17. Hart JP, Peeters P, Verbist J, Deloose K, Bosiers M (2006) Do device characteristics impact outcome in carotid artery stenting? J Vasc Surg 44 725-730. Link: https://bit.ly/3dMq641
18. Tadros RO, Spyris CT, Vouyouka AG, Chung C, Krishnan P, et al. (2012) Comparing the embolic potential of open and closed cell stents during carotid angioplasty and stenting. J Vasc Surg 56: 89-95. Link: https://bit.ly/2WQSGtV

19. Hopf-Jensen S, Marques L, Preiß M, Müller-Hülsbeck S (2015) Initial Clinical Experience With the Micromesh Roadsaver Carotid Artery Stent for the Treatment of Patients With Symptomatic Carotid Artery Disease. J Endovasc Ther 22: 220-225. Link: https://bit.ly/2T041GV

20. Timaran $\mathrm{CH}$, Rosero EB, Higuera A, Ilarraza A, Modrall JG, et al. (2011) Randomized clinical trial of open-cell vs closed-cell stents for carotid stenting and effects of stent design on cerebral embolization. J Vasc Surg 54: 1310-1316. Link: https://bit.ly/3bnz9GJ

21. Wissgott C, Schmidt W, Brandt C, Behrens P, AndresenR (2015) Preliminary Clinical Results and Mechanical Behavior of a New Double-Layer Carotid Stent. J Endovasc Ther 22: 634-639. Link: https://bit.ly/2SZzjxS

22. Kabbasch C, Bangard C, Liebig T, Majd P, Mpotsaris A, et al. (2016) The Dual Layer Casper Micromesh Stent: Taking Advantage of FlowDiverting Capabilities for the Treatment of Extracranial Aneurysms and Pseudoaneurysms. Cardiovasc Intervent Radiol 39: 472-476. Link: https://bit.ly/2T0xqRD
Discover a bigger Impact and Visibility of your article publication with

\section{Peertechz Publications}

\section{Highlights}

* Signatory publisher of ORCID

* Signatory Publisher of DORA (San Francisco Declaration on Research Assessment)

* Articles archived in worlds' renowned service providers such as Portico, CNKI, AGRIS, TDNet, Base (Bielefeld University Library), CrossRef, Scilit, J-Gate etc.

* Journals indexed in ICMJE, SHERPA/ROMEO, Google Scholar etc.

* OAI-PMH (Open Archives Initiative Protocol for Metadata Harvesting)

* Dedicated Editorial Board for every journa

* Accurate and rapid peer-review process

* Increased citations of published articles through promotions

* Reduced timeline for article publication

Submit your articles and experience a new surge in publication services (https://www.peertechz.com/submission).

Peertechz journals wishes everlasting success in your every endeavours.

Copyright: ( $) 2020$ Cabral de Andrade G, et al. This is an open-access article distributed under the terms of the Creative Commons Attribution License, which permits unrestricted use, distribution, and reproduction in any medium, provided the original author and source are credited. 